TAO, Vol. 15, No. 4, 647-666, November 2004

\title{
Relocation of Eastern Taiwan Earthquakes and Tectonic Implications
}

\author{
Hao Kuochen ${ }^{1, *}$, Yih-Min Wu ${ }^{1}$, Chien-Hsin Chang ${ }^{1}$, Jyr-Ching Hu${ }^{2}$, and Wen-Shan Chen ${ }^{2}$
}

(Manuscript received 18 August 2003, in final form 10 August 2004)

\begin{abstract}
We relocated 6,173 shallow earthquakes and determined focal mechanism solutions of thirty-three $M_{L} \geq 5.0$ events in the eastern Taiwan region (bounded by $22.7^{\circ} \mathrm{N}, 120.8^{\circ} \mathrm{E} ; 24.5^{\circ} \mathrm{N}, 121.5^{\circ} \mathrm{E} ; 24.3^{\circ} \mathrm{N}, 122.3^{\circ} \mathrm{E}$ and $22.5^{\circ} \mathrm{N}, 121.6^{\circ} \mathrm{E}$ ) in order to investigate their tectonic implications. Our results suggest that the distribution of the relocated earthquakes generally agrees with the fault plane determined from the focal mechanism solutions. The Longitudinal Valley ( $\mathrm{LV}$ ) is an east-dipping seismic suture zone that separates two different tectonic regions. On the left-hand side of the $L V$, shallow earthquakes and normal fault-type focal mechanism were found in the Central Range region. But on the right-hand side of the $L V$, most events that occurred in the Philippine Sea Plate (PSP) were the thrust-type, especially for the southern portion and a few normal and strike-slip focal mechanism events were observed in the northern portion. The tectonics of eastern Taiwan can be classified from south and north into two regions, and there may exist a structure or boundary at about latitude $23.5^{\circ} \mathrm{N}$ with a strike of $\mathrm{N}^{110^{\circ}} \mathrm{E}$. In the northern portion of eastern Taiwan, the plate boundary appears to be an east-dipping plane defined by the earthquake distribution. The focal mechanism solutions determined in this zone show thrust type faulting and agreed with this boundary plane (strike $\mathrm{N20}^{\circ} \mathrm{E}$ and dip about $50^{\circ}$ ). In this region, the Eurasia Plate (EP) dips to the east, and the PSP bends and dips to west. Thus, shallow earthquakes with normal and strikeslip focal mechanisms were observed in the offshore area of this region. On the other hand, the southern part of eastern Taiwan exhibits simple tectonics conditions. The EP subducts to the east under the PSP. The $L V$ is a suture zone dipping to the east, and most events have occurred on the righthand side of the LV. Focal mechanism solutions of these events were thrust-
\end{abstract}

${ }^{1}$ Seismological Observation Center of the Central Weather Bureau, Taipei, Taiwan, ROC

2 Department of Geosciences, National Taiwan University, Taipei, Taiwan, ROC

* Corresponding author address. Dr. Hao Kuochen, Seismological Observation Center of the Central Weather Bureau, Taipei, Taiwan, ROC; E-mail: kuochen@scman.cwb.gov.tw 
type with strike about $\mathrm{N} 25^{\circ} \mathrm{E}$ and $\operatorname{dip} 54^{\circ}$ to the east.

\author{
(Key words: Earthquake, Focal mechanism solution, Tectonics, Eastern Taiwan, \\ Plate boundary)
}

\title{
1. INTRODUCTION
}

Taiwan is located at plate boundaries; the Philippine Sea Plate (PSP) subducts northward under the Eurasia Plate (EP) along the Ryukyu trench, and the EP subducts eastward under the PSP off the southern tip of Taiwan. Thus, the eastern Taiwan region is the suture zone of these two plates. Numerous studies of this region have been published using available geophysical and geological data (e.g., Barrier and Angelier 1986; Ho 1986; Teng 1990; Tsai 1986; Wu 1978; Wu et al. 1997; Chang et al. 2000). From the north to the south of eastern Taiwan, geological and plate motion data reveal different patterns of arc-continent collision evolution stages (e.g., Chemenda et al. 2001; Lee et. al. 1991; Malavieille et al. 2002; Yu et al. 1990; Yu and Kuo 2001). The northern part of eastern Taiwan, near Hualien, is the subduction and collision complex of the Taiwan-Ryukyu junction area (e.g., Hsu 2001). Data from trilateration and leveling networks and the GPS (Global Positioning System) network in this area show that the block motions are $25-36 \mathrm{~mm} \mathrm{yr}^{-1}$ in the direction of $313-324^{\circ}$ (Yu et al. 1990; Yu and Kuo 2001, Fig. 1). To the South of the Chimei fault, is the Luzon forearc deformation region (e.g., Chemenda et al. 1997; Cheng and Wang 2001; Cheng et al. 2002; Malavieille et al. 2002), and the block motions are $44-81 \mathrm{~mm} \mathrm{yr}^{-1}$ in the direction of $298-318^{\circ}$ from the GPS network data. The trilateration and leveling data, the GPS data, and paleomagnetic studies (e.g., Lee et al. 1991) are all in agreement with a clockwise rotation of the Coastal range.

The interactions between these two plates (PSP and EP) have resulted in a very complicated crustal structure in the Taiwan region. This complexity and not well-determined seismic velocity structure can cause large uncertainties in earthquake location. The location uncertainty of routinely determined hypocenters (from a layered velocity model) is typically many times larger than the source dimension of the earthquakes themselves. This limits the study of the fine crustal structure using the seismicity data, especially, for eastern Taiwan (which is a suture zone of the PSP and EP). Thus, the geometrical relationship between these two plates in eastern Taiwan is not well known. For example, in the Hualien area, seismogenic patterns are very complex. It is difficult to use the earthquake hypocenters to define the actual fault plane from focal mechanisms (e.g., Kao and Jian 2001). Obviously, improving the earthquake location is one of the ways to understand the relationship between these two plates in eastern Taiwan. Recently, Waldhauser and Ellsworth (2000) proposed a hypo-DD method to minimize errors due to un-modeled velocity structure without the use of station corrections. Residuals between observed and theoretical travel time differences are minimized for pairs of closely spaced earthquakes at each station while linking together all observed event-station pairs. The hypo-DD method can be applied to locate large amounts of earthquakes over a large distance. Furthermore, the earthquakes in eastern Taiwan have occurred more frequently than in other Taiwan regions. For analyzing the potential for large earthquake occurrences, some 


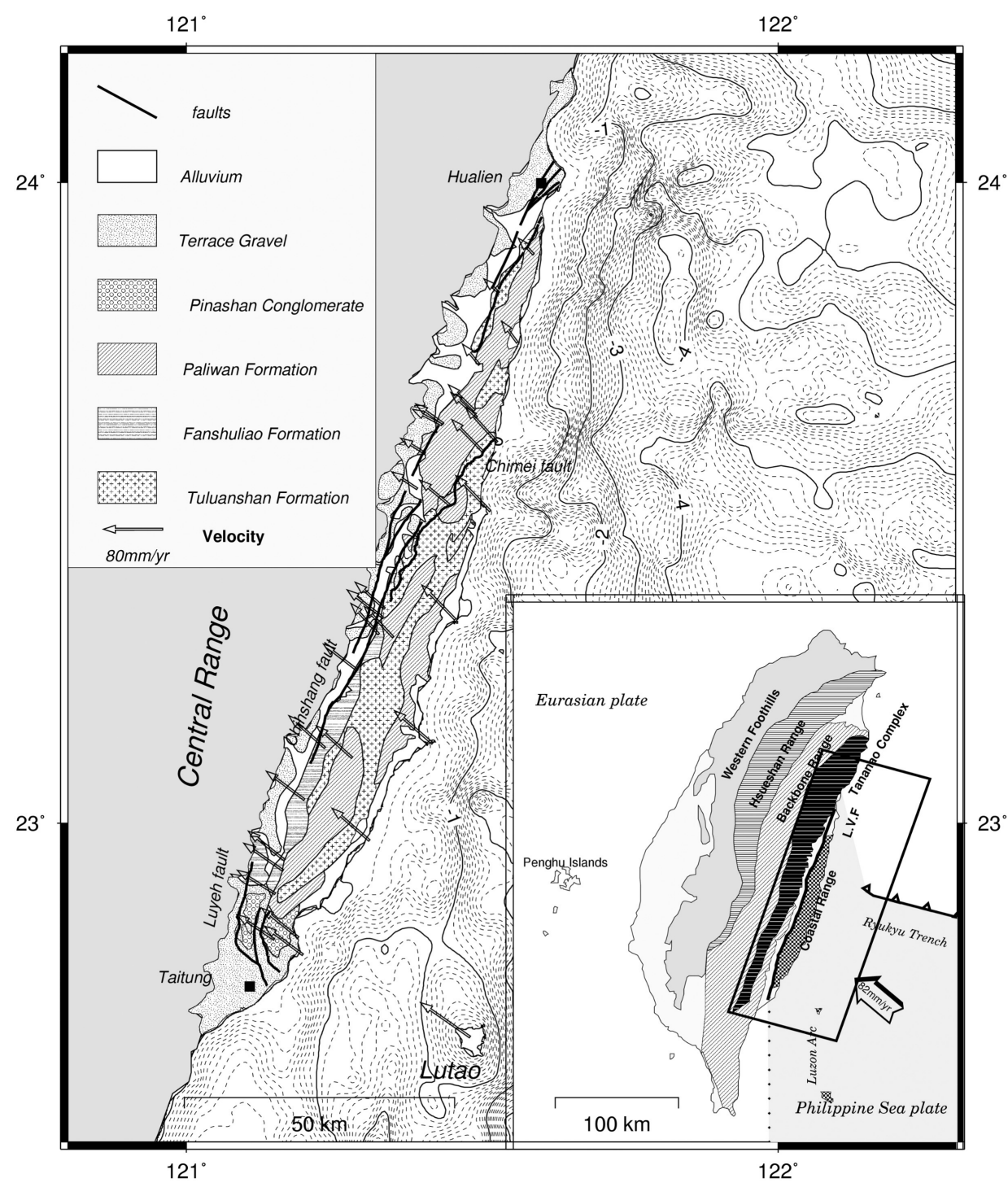

Fig. 1. Geology (Ho 1986) and geodynamic of eastern Taiwan and its offshore topography. The open arrows indicate the GPS velocity vectors relative to Penghu station (Yu and Kuo 2001). The bathymetric data are from Liu et al. 1996; 1998. Below right: Tectonic setting of Taiwan (modified from Ho 1986). The rectangle shows the region in this study. The large open arrow and number indicate the relative-plate-motion vector between the Philippine Sea and Eurasian plates as determined by Yu et al. 1997. LVF: Longitudinal Valley Fault. 
researchers have monitored the most active segment of the LV, the Chihshang fault (Fig. 1), for a long time and have made ongoing calculations of the slip rate in this region to predict forthcoming locking stages, which increase earthquake hazard (Angelier et al. 2000; Lee et al. 2003). In addition, seismicity in the Chihshang region is the result of a narrow SE-dipping seismic zone (Chen and Rau 2002); and frequent seismicity in this seismic zone might explain the high creep rate of the Chinshang fault. Therefore, studying seismic patterns can make a helpful contribution to better understanding and interpreting surface ruptures.

Thus, in this study we will apply the hypo-DD technique to relocate eastern Taiwan earthquakes from 1991 to 2002 and determine the focal mechanism solutions of the larger events in order to study seismic patterns and the relationship between these two plates in eastern Taiwan.

\section{TECTONIC SETTING}

Taiwan is located in the active arc-continent collision region between the Luzon volcanic arc of the PSP and the Eurasian continent. To the northeast of Taiwan lies the northwestwardsubducting Ryukyu Trench, and to the south lies the eastward-subducting Manila Trench. Relative to the Penghu Islands on the EP, the PSP is moving northwest $\left(306^{\circ}\right)$ at a rate of about $8.2 \mathrm{~cm} \mathrm{yr}^{-1}$ (Yu et al. 1997, Fig. 1). The surface geology of Taiwan can be divided into six units: (1) the Coastal Plain, (2) the Western Foothills, (3) the Hsüehshan and the Backbone Range, (4) the Tananao Metamorphic Complex, (5) the LV, and (6) the Coastal Range. The Coastal plain consists of Quaternary alluvial sediments. East of the Coastal Plain are the Western Foothills, a nonmetamorphic fold-and-thrust belt of Neogene clastic sediments. The Hs? ehshan and Backbone Range is a fold-and-thrust belt composed of an argillite-slate series. The oldest stratigraphic member in Taiwan is the Tananao Complex formed in pre-Tertiary. East of the Tananao complex, the LV separates the Coastal Range and the Central Range and is commonly considered an active collision boundary between the PSP and EP (e.g., Wu 1978; Barrier and Angelier 1986; Ho 1986; Tsai 1986). The Coastal Range comprises Neogene andesitic volcanic units and associated flyschoid and turbidite sediments of the accreted Luzon-arcTrench system. The intrusion and extrusion of these volcanic rocks formed an igneous complex exposed in the middle part of the Coastal Range and also in the two southeastern offshore islands, Lutao and Lanshu (e.g., Ho 1986).

The collisional history of Luzon arc-trench system can be illustrated by composition rocks in the Coastal Range (e.g., Chen 1989; Teng 1990, Fig. 1). In the Miocene, Tuluanshan andesitic deposits indicate that the arc was situated away from continental influence. The depositions of Fanshuliao-Paliwan sediments are in a deep-sea setting. In the Lower Pliocene Fanshuliao, the fine-grained continent-derived detritus shows that the arc moved sufficiently close to receive sediment from the continent. In the Upper Pliocene Paliwan Formation, the coarse-grained continent-derived sediments reveals that the continental margin was rapidly uplifted, to from high mountains. The gravels and Pinashan Conglomerate deposits in the Pleistocene derived from the pre-Tertiary metamorphic basement of the Central Range (Ho 1986). 


\section{DATA AND ANALYSIS}

The Central Weather Bureau (CWB) and its predecessor have been responsible for monitoring earthquakes in the Taiwan region since 1896. Since 1990, the CWB seismic network (CWBSN) consists of a central recording system with 73 telemetered stations (Fig. 2), each equipped with 3-component S13 seismometers. Seismic signals digitized at 12 bits and 100 samples per second from each station are transmitted via dedicated telephone line to a central

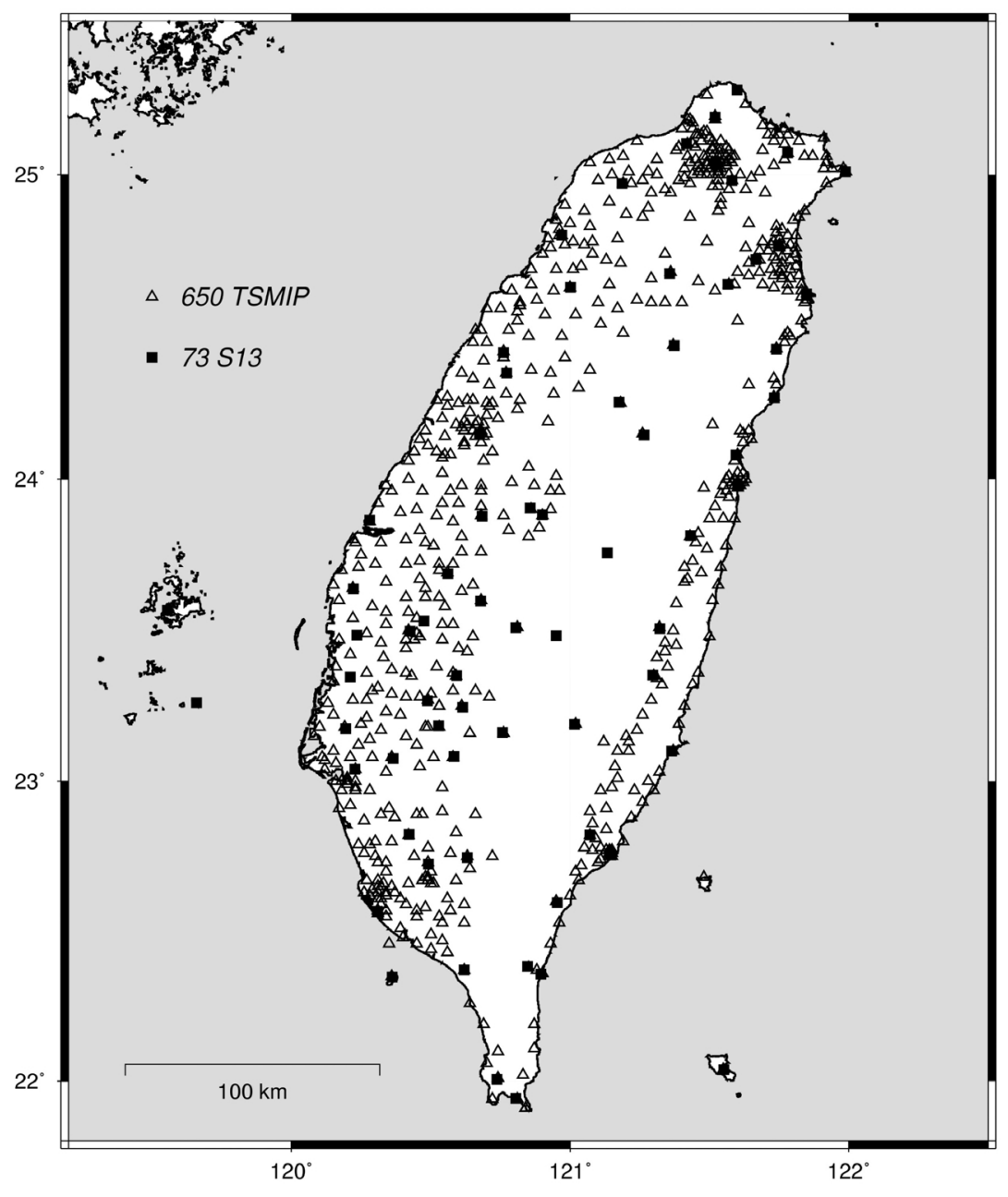

Fig. 2. Station distributions of the Central Weather Bureau Seismic Network (CWBSN: solid squares) and the Taiwan Strong Motion Instrumentation Program (TSMIP: open triangles). 
station in Taipei. Large amounts of earthquake data have been recorded by the CWBSN. A total of 6,625 events from January 1 in 1991 to December 31 in 2002 were used in this study for earthquakes relocation. The selection was based on the following criteria: (1) earthquakes were located in the region bounded by bounded by $22.7^{\circ} \mathrm{N}, 120.8^{\circ} \mathrm{E} ; 24.5^{\circ} \mathrm{N}, 121.5^{\circ} \mathrm{E} ; 24.3^{\circ} \mathrm{N}$, $122.3^{\circ} \mathrm{E}$ and $22.5^{\circ} \mathrm{N}, 121.6^{\circ} \mathrm{E}$; (2) Each event has clear $\mathrm{P}$ or $\mathrm{S}$ wave arrivals at 6 or more stations; (3) Earthquake magnitude $\left(\mathrm{M}_{\mathrm{L}}\right)$ is greater than 3 and focal depth is less than $40 \mathrm{~km}$.

In this study, a two-step location technique will be employed for earthquake relocation. These two processes can both enhance an event's absolute and relative positions. In first step, we use the three-dimensional velocity structure location method (3DLOC; Thurber and EberhartPhillips 1999) to improve each event's location precision. The hypo-DD equations are built according to Geiger's equation for earthquake location and the method calculates travel times in a layered model velocity model for the current hypocenters at the station where the phase was recorded. The double-difference residuals for pairs of earthquakes at each station are minimized by weighted least squares using the method of singular value decomposition (SVD) or the conjugate gradients method (LSQR) (Waldhauser and Ellsworth 2000). The SVD method can be useful for examining small systems (about 100 events), and the LSQR method is able to solve for large systems efficiently (thousands of events). Therefore, we will use the LSQR method to relocate the events. In applying the ray tracing method of Thurber (1993), the threedimension P and S wave velocity structure model determined by Chen and Shin (1998) was used in this study and the layered model determined in their study was also employed in the hypo-DD relocation process.

The focal mechanisms of $\mathrm{M}_{\mathrm{L}} \geq 5.0$ events were also determined in this study based on the relocation hypocenters and the first P polarities from the CWBSN and the Taiwan Strong Motion Instrumentation Program stations (TSMIP). The TSMIP, a total of 650 high-resolution wide-dynamic-range digital accelerographs have been installed at free-field sites throughout the densely populated areas of Taiwan (Fig. 2). Several tens of thousands of high-quality digital accelerograms were collected from numerous earthquakes occurring over the last ten years. These records, combined with the conventional seismograms recorded by the CWBSN, provide an excellent database for improving earthquake focal mechanism determination.

\section{RESULTS}

A total of 6,173 earthquakes were relocated using the hypo-DD method, about $93 \%$ of the total selected events. The epicentral and hypocentral distributions of the CWBSN and hypoDD results are shown in Figs. 3 and 4, respectively. Comparing with these two results, epicentral and hypocentral distributions of the CWBSN results are more scattered than the hypo-DD results. The distributions of the hypo-DD results present in groups or linear patterns. From three statistical error measurements for earthquake location, i.e., the root-mean-square (RMS) of travel time residuals, the error in depth (ERZ) and the error in epicenter (ERH; Flinn 1965) (Table 1), it shows the 3DLOC can improve the location quality. Comparing the epicentral distribution of the 3DLOC and hypo-DD with the CWBSN results, there exists a systematic shift in the relocation results. The epicentral distribution of the 3DLOC results moved about 
$5.3 \pm 4.1 \mathrm{~km}$ with an averaged direction of $\mathrm{N} 74^{\circ} \mathrm{W}$ from the CWBSN results (Fig. 5a). Epicentral distribution of the hypo-DD+3DLOC results moved about $5.2 \pm 4.1 \mathrm{~km}$ with an averaged direction of $\mathrm{N}^{\circ} 6^{\circ} \mathrm{W}$ from the CWBSN results (Fig. 5b). On the contrary, the differences of the epicentral distribution between the hypo-DD + 3DLOC and 3DLOC were relatively small about $2.5 \pm 2.0 \mathrm{~km}$ and no systematic shift (Fig. 5c). Generally, the relocation epicenters move westward about $5 \mathrm{~km}$. To compare the relocation results of the previous study in the Hualien region (Lin et al. 1998), the relocation results in this study showing the westward shift seems to conflict with the results in the Hualien region. But the results have been tested by a previous study, which used $\mathrm{P}$ arrival and S-P time differences of those events; the CWBSN location shift westward would be in better agreement with near source P arrival and S-P time difference observations (Wu et al. 1998). In addition, similar results were shown in Cheng et al. (2002) and Chen and Shin (1998).
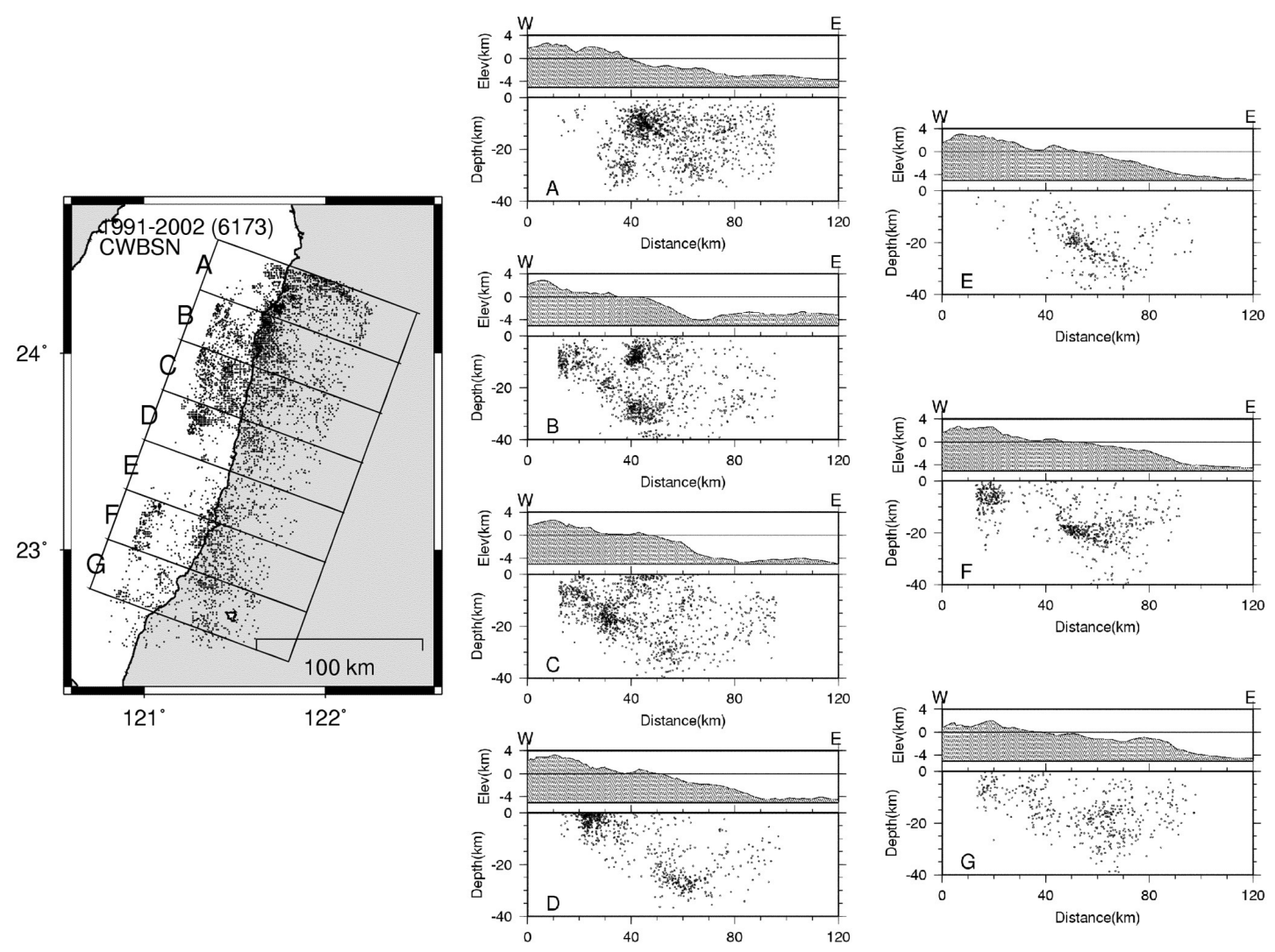

Fig. 3. The epicenters and the $\mathrm{N} 110^{\circ} \mathrm{E}$ directional hypocentral profiles from CWBSN catalogs. 

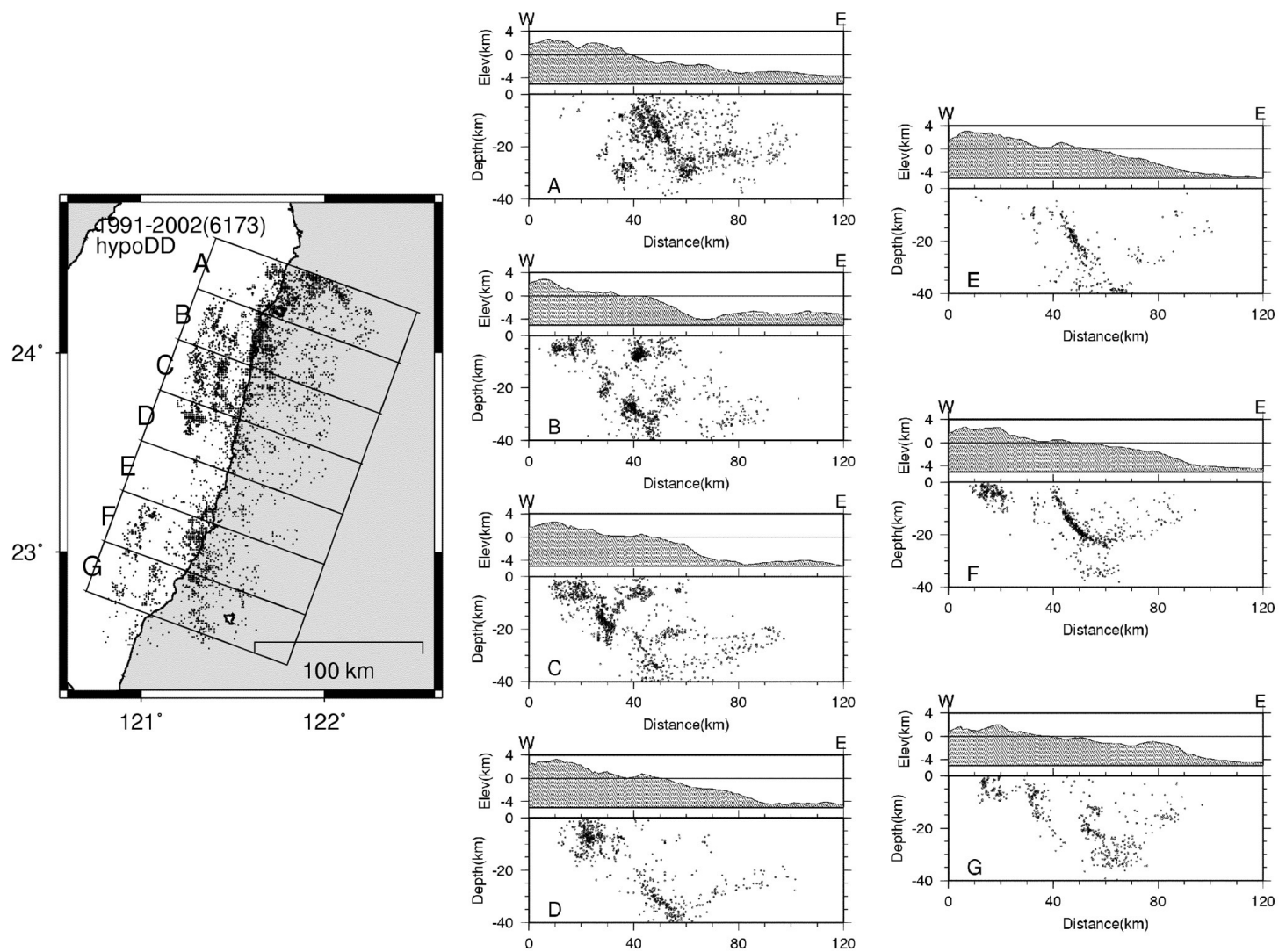

Fig. 4. The epicenters and the $\mathrm{N} 110^{\circ} \mathrm{E}$ directional hypocentral profiles from hypo-DD relocation.

Table 1. The statistical error measurements of the ERH, ERZ, and RMS from the CWBSN, and 3DLOC in this study.

\begin{tabular}{|c|c|c|}
\hline & CWBSN & 3DLOC \\
\hline RMS $(\mathrm{sec})$ & $0.35 \pm 0.11$ & $0.29 \pm 0.10$ \\
\hline $\operatorname{ERH}(\mathrm{km})$ & $1.02 \pm 0.53$ & $0.44 \pm 0.48$ \\
\hline $\operatorname{ERZ}(\mathrm{km})$ & $1.13 \pm 1.30$ & $0.67 \pm 1.02$ \\
\hline
\end{tabular}




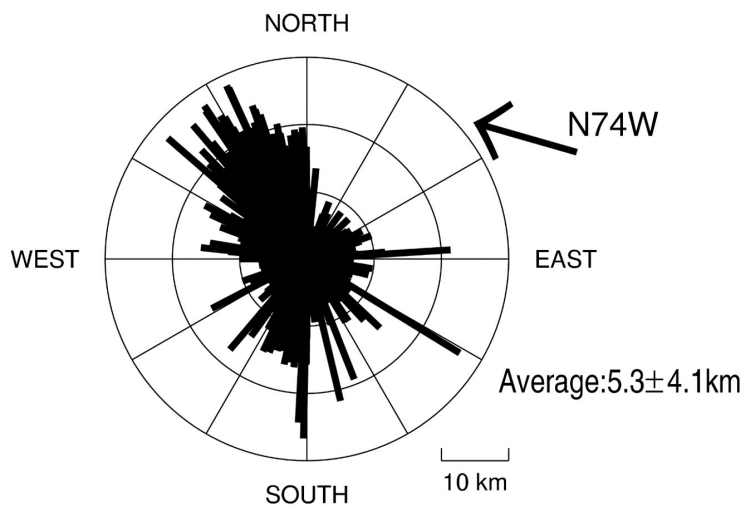

3DLOC V.S. CWBSN

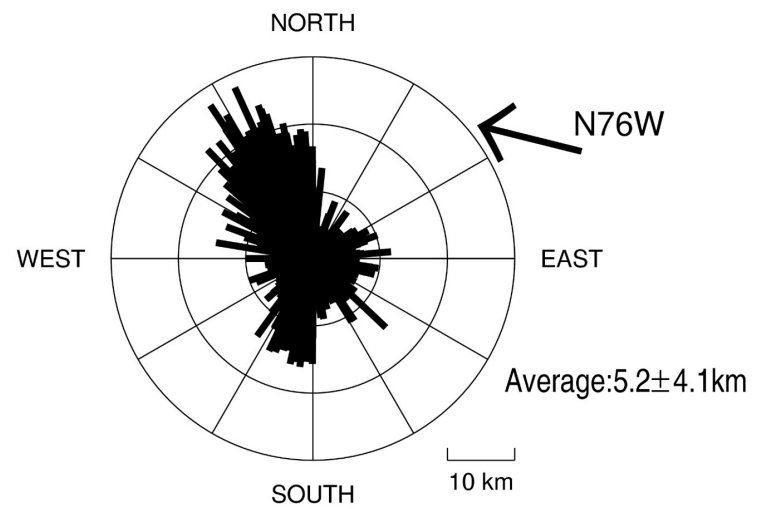

3DLOC+hypoDD V.S. CWBSN

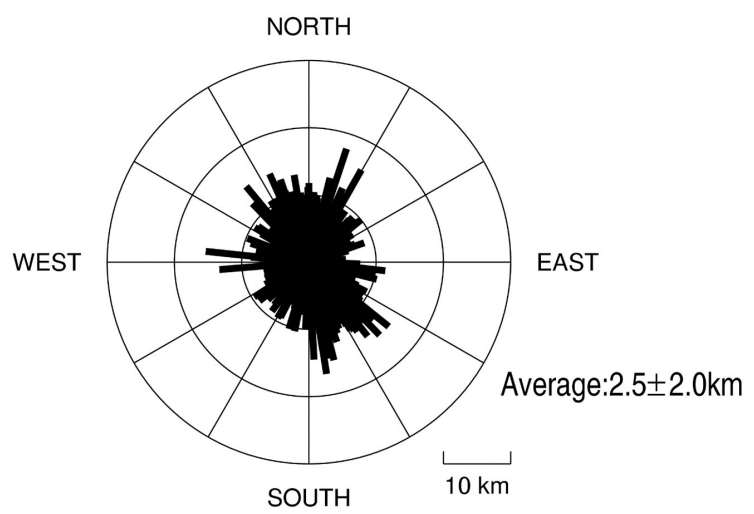

3DLOC+hypoDD V.S. 3DLOC
Fig. 5. The rose diagrams reveal the shifting distance and azimuth of the earthquake relocation. Above: 3DLOC to CWBSN; middle: hypoDD + 3DLOC to CWBSN; below: hypoDD +3 DLOC to 3DLOC. 
A total of thirty-three focal mechanism solutions of the $\mathrm{M}_{\mathrm{L}} \geq 5.0$ events were determined (Table 2) based on the relocation hypocenters and the first $P$ polarities from the CWBSN and TSMIP. After relocation, we have more precise take-off angles and azimuth readings. By adding the TSMIP polarities, we have increased not only the total polarity readings, but also polarities near the nodal planes (which help to constraint the fault plane) (Fig. 6). In Fig. 6, A and B show focal mechanism solutions of 2 earthquakes determined from the CWBSN location results and first $\mathrm{P}$ polarities, while $\mathrm{C}$ and $\mathrm{D}$ show focal mechanism solutions of the same two events based on this study and the first P polarities from the CWBSN and TSMIP. Obviously, the solutions were greatly improved in this study. All of the first P motion polarities agree with this focal mechanism, which strongly supports the notion that the focal mechanism established in this study has good control and that the source location of this study results must have been reliably determined.

Figure 7 shows the epicentral distribution of the relocated events and thirty-three focal mechanism solutions determined in this study. Detail focal mechanism solution parameters are given in Table 2. Most of the focal mechanism solutions of those events are the thrust-type (events: 1, 2, 3, 4, 5, 8, 9, 10, 11, 12, 13, 15, 19, 22, 23, 24, 26, 30, 31, and 33), eight are normal-type (events: $6,7,16,17,20,21,27$, and 28), and five are strike-slip type solutions (events 14, 18, 25, 29, and 32).

In general, the epicentral distributions can be divided into three linear patterns and coincide with the topography (Fig. 7). Zone aa' is located in eastern side of the Central Range and most normal-type focal mechanism events were found in this region. Zone bb' is located in the left side of LV, a strike-slip focal mechanism event was found in the south portion and two thrust-type focal mechanism events were found in the northern portion. Zone cc' is located s in the right-hand side of LV. Most of the thrust-type focal mechanism events were found, especially in the southern portion of this zone. Generally, the southern portion of the study region has more simple focal mechanisms than the northern portion.

\section{DISCUSSION AND CONCLUSIONS}

In this study, the geometric distribution of the relocated events is in general agreement with the focal mechanism solutions. Some researchers also offered focal mechanisms to interpret the tectonic environment in eastern Taiwan (Cheng and Wang 2001; Lin et al. 1998; Lin 2002; Rau and Wu 1998); and comparing the fault plane solutions of these studies with our data, it is clear that most solutions agree with our data. Further, the focal mechanisms determined by CWBSN and TSMIP can give more constraint of the nodal plane. Figure 8 shows seven hypocentral distribution profiles and thirty-three events focal mechanism solutions in a lateral projection along the $\mathrm{N} 110^{\circ} \mathrm{E}$ direction. The focal depths in zone aa' were very shallow and most events occurred within $10 \mathrm{~km}$. Most normal fault focal mechanisms were found in this zone (Fig. 8, events: 16, 17, 18, 27, and 28 in profile $\mathrm{C}$ and F). This observation agrees with recent GPS measurements (e.g., Yu and Chen 1994; Yu et al. 1997) and the recent study on focal mechanisms by Lin et al. (1998) who found that most extensional earthquakes were located in the area of the Tananao complex. Recent studies indicate that this phenomenon 
Table 2. Source parameters of studied earthquakes.

\begin{tabular}{|c|c|c|c|c|c|c|c|c|c|c|c|}
\hline No. & Origin Time, UT* & Long.* & Lat." & Depth* & $\mathrm{M}_{\mathrm{T}}$; & Strike $(1)_{i}$ & Dip( (1) & Rake (1) H & Strike(2) & $\operatorname{Dip}(2)_{+4}$ & Rake(2): \\
\hline 1 & $1991 / 03 / 02 / 04: 56: 39.29$ & 121.750 & 24.044 & 24.6 & 5.0 & 18 & 63 & 77 & 225 & 30 & 114 \\
\hline 2 & $1991 / 10 / 12 / 05: 08: 41.93$ & 121.436 & 22.869 & 17.5 & 5.3 & 30 & 58 & 124 & 200 & 66 & 72 \\
\hline 3 & $1991 / 10 / 18 / 03: 52: 10.01$ & 121.754 & 23.777 & 20.4 & 5.0 & 25 & 63 & 85 & 216 & 27 & 100 \\
\hline 4 & $1991 / 12 / 05 / 15: 48: 23.47$ & 121.399 & 22.678 & 28.7 & 5.2 & 12 & 25 & 85 & 198 & 65 & 92 \\
\hline 5 & $1992 / 04 / 19 / 18: 32: 20.90$ & 121.575 & 23.841 & 14.9 & 5.6 & 197 & 47 & 21 & 92 & 75 & 135 \\
\hline 6 & $1992 / 10 / 03 / 13: 56: 41.49$ & 121.412 & 22.630 & 38.9 & 5.7 & 291 & 56 & -82 & 97 & 35 & -102 \\
\hline 7 & $1992 / 12 / 28 / 05: 23: 25.84$ & 121.803 & 23.864 & 25.3 & 5.3 & 193 & 83 & -54 & 293 & 37 & -168 \\
\hline 8 & $1995 / 05 / 27 / 18: 11: 12.47$ & 121.465 & 23.008 & 20.7 & 5.2 & 18 & 40 & 77 & 215 & 51 & 101 \\
\hline 9 & $1995 / 06 / 06 / 23: 21: 24.63$ & 121.457 & 23.014 & 19.5 & 5.0 & 15 & 40 & 70 & 220 & 53 & 106 \\
\hline 10 & $1995 / 12 / 18 / 16: 17: 54.79$ & 121.692 & 24.018 & 30.0 & 6.0 & 15 & 61 & 35 & 266 & 60 & 146 \\
\hline 11 & $1995 / 12 / 20 / 23: 56: 37.00$ & 121.713 & 24.049 & 39.2 & 5.1 & 201 & 44 & 110 & 354 & 49 & 72 \\
\hline 12 & $1996 / 12 / 18 / 11: 20: 24.58$ & 121.358 & 22.821 & 17.4 & 5.0 & 57 & 48 & 143 & 174 & 63 & 48 \\
\hline 13 & $1997 / 11 / 14 / 04: 29.51 .84$ & 121.758 & 24.160 & 10.3 & 5.5 & 200 & 80 & 52 & 97 & 39 & 164 \\
\hline 14 & $1998 / 01 / 18 / 19: 56: 52.19$ & 121.089 & 22.725 & 6.4 & 5.1 & 105 & 89 & 160 & 196 & 70 & 1 \\
\hline 15 & $1999 / 06 / 10 / 07: 18: 00.65$ & 121.727 & 23.725 & 29.5 & 5.2 & 162 & 75 & 135 & 264 & 47 & 21 \\
\hline 16 & $1999 / 09 / 20 / 20: 40: 04.10$ & 121.342 & 23.962 & 6.9 & 5.1 & 20 & 35 & -105 & 218 & 56 & -80 \\
\hline 17 & $1909 / 09 / 23 / 21: 39: 01.34$ & 121.388 & 23.941 & 6.8 & 5.2 & 176 & 55 & -78 & 336 & 37 & -107 \\
\hline 18 & $1999 / 09 / 25 / 20: 51: 52.27$ & 121.004 & 23.130 & 7.0 & 5.1 & 349 & 61 & -16 & 87 & 76 & .150 \\
\hline 19 & $2000 / 03 / 16 / 00: 37: 54.97$ & 121.622 & 22.734 & 21.4 & 5.0 & 223 & 50 & 102 & 25 & 41 & 76 \\
\hline 20 & $2000 / 07 / 13 / 22: 01: 10.01$ & 121.827 & 23.940 & 8.2 & 5.1 & 15 & 45 & -112 & 225 & 49 & -69 \\
\hline 21 & $2000 / 07 / 14 / 23: 04: 33.72$ & 121.803 & 23.947 & 9.4 & 5.1 & 197 & 85 & -76 & 306 & 15 & -160 \\
\hline 22 & $2000 / 08 / 23 / 00: 49: 17.24$ & 121.635 & 23.636 & 32.1 & 5.5 & 18 & 72 & 65 & 254 & 30 & 142 \\
\hline 23 & $2000 / 09 / 10 / 08: 54: 46.19$ & 121.584 & 24.085 & 12.9 & 6.2 & 188 & 28 & 48 & 54 & 70 & 110 \\
\hline 24 & $2000 / 11 / 29 / 11: 00: 33.96$ & 121.768 & 23.857 & 27.2 & 5.1 & 18 & 80 & 54 & 275 & 37 & 163 \\
\hline 25 & $2000 / 12 / 29 / 18: 03: 29.68$ & 121.884 & 24.361 & 16.2 & 5.3 & 8 & 80 & -155 & 273 & 65 & -11 \\
\hline 26 & $2001 / 01 / 22 / 23: 27: 19.34$ & 122.134 & 24.319 & 24.0 & 5.2 & 304 & 25 & 135 & 76 & 73 & 72 \\
\hline 27 & $2001 / 06 / 19 / 05: 16: 15.42$ & 121.077 & 23.177 & 9.4 & 5.4 & 51 & 41 & .99 & 243 & 50 & -82 \\
\hline 28 & $2001 / 06 / 19 / 05: 43: 38.97$ & 121.098 & 23.197 & 4.4 & 5.2 & 131 & 53 & -65 & 273 & 44 & -119 \\
\hline 29 & $2001 / 10 / 26 / 10: 42: 40.70$ & 122.022 & 23.710 & 28.9 & 5.1 & 25 & 70 & -165 & 290 & 76 & -21 \\
\hline 30 & $2002 / 03 / 31 / 06: 52: 50.72$ & 122.192 & 24.140 & 21.4 & 6.8 & 299 & 36 & 129 & 74 & 63 & 65 \\
\hline 31 & 2002/04/03/18:06:10.71 & 121.868 & 24.322 & 18.5 & 5.3 & 17 & 80 & 67 & 265 & 25 & 156 \\
\hline 32 & $2002 / 06 / 14 / 07: 22: 24.35$ & 121.653 & 23.507 & 36.5 & 5.2 & 13 & 68 & 18 & 276 & 73 & 157 \\
\hline 33 & $2002 / 09 / 24 / 22: 43: 23.57$ & 121.076 & 22.669 & 4.6 & 5.2 & 250 & 30 & 75 & 87 & 61 & 98 \\
\hline
\end{tabular}

* Origin time (year/month/day/hour:minute:second), epcentral locations ( $\left.{ }^{\circ} \mathrm{N},{ }^{\circ} \mathrm{E}\right)$, depth(km). And local magntudes are reports by the Central Weather Bureau.

\# (1) and (2) are revealed fault plane 1 and fault plane 2, respectively. 

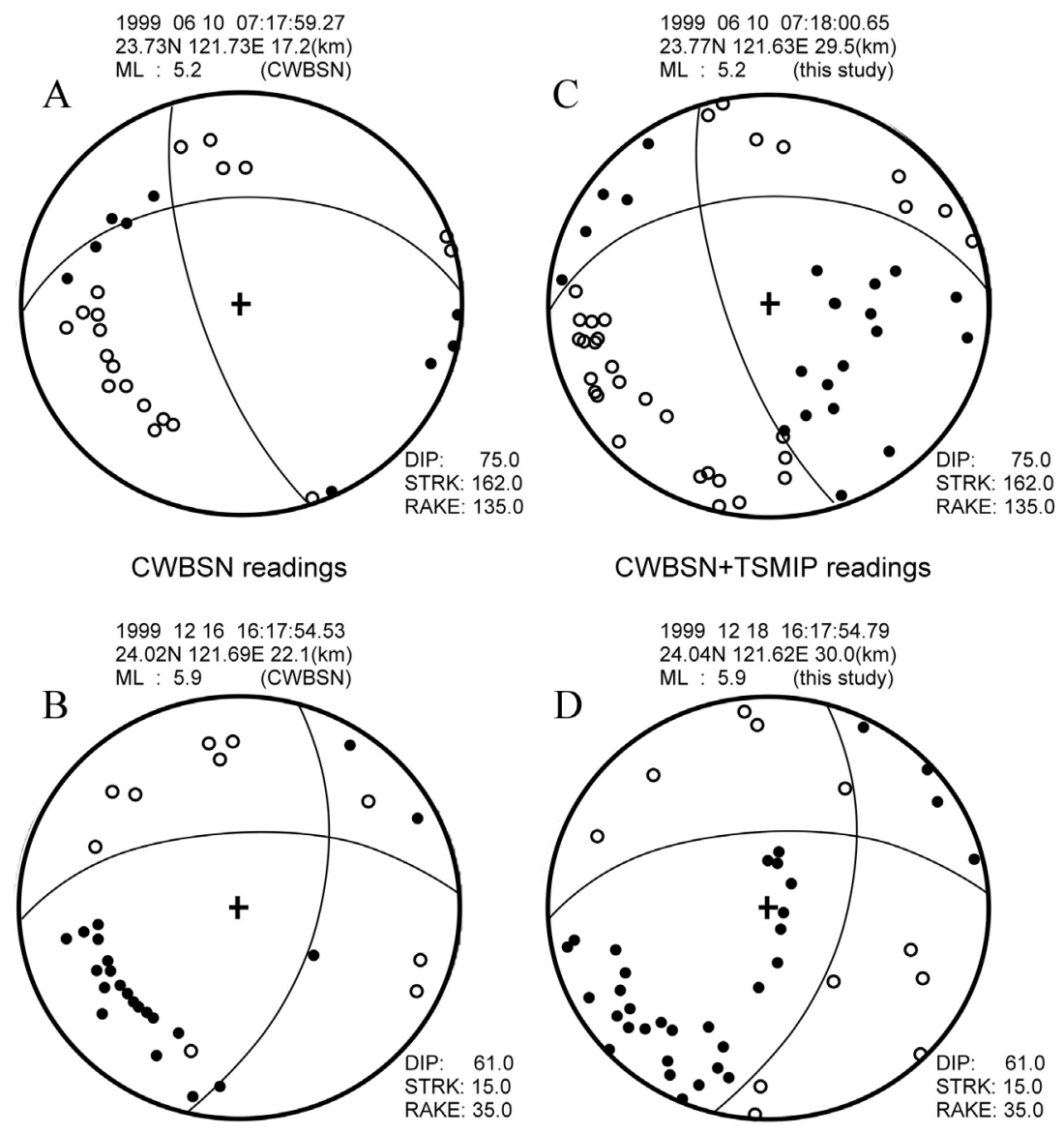

Fig. 6. The two examples of improving focal mechanism determination. Left: Pmotions from the CWBSN. Right: P-motions from the CWBSN and the TSMIP after relocation.

results from extension occuring during the late stage of mountain building (Crespi 1996; Crespi et al. 1996). The physical and numerical modeling results also indicated that crustal extension occurs around the crest of the Central Range because of gravitational spreading (Wang and Hung 2002).

The focal depths of earthquakes in zone bb' were shallow $(0-15 \mathrm{~km})$ in the southern portion, and the events occurred at deeper positions $(15-30 \mathrm{~km})$ in the northern portion. In seismic zone cc', the hypocentral distribution is more complicated. In terms of the epicentral and hypocentral distributions (Figs. 7 and 8) we found that the LV is an east-dipping seismic zone. In the profiles of $\mathrm{B}, \mathrm{C}$, and $\mathrm{D}$, the seismic zone of the aa', bb', and cc' are linked to as an east-dipping seismic zone about dip $50^{\circ}$ and strike $\mathrm{N} 20^{\circ} \mathrm{E}$ on the eastern side of the LV. Also, 
most of the focal mechanism solutions (events: 1, 2, 8, 9, 10, 11, 12, 22, 23, and 31) determined in this zones bb' and cc' are thrust-types and fault planes agree with this seismic zone. The average strike and dip of those events from focal mechanism solutions are $\mathrm{N} 25^{\circ} \mathrm{E}$ and dip $54^{\circ}$, respectively. There exists a seismic zone dipping to the west from the offshore area, but no significant focal mechanism solution is found in this area.

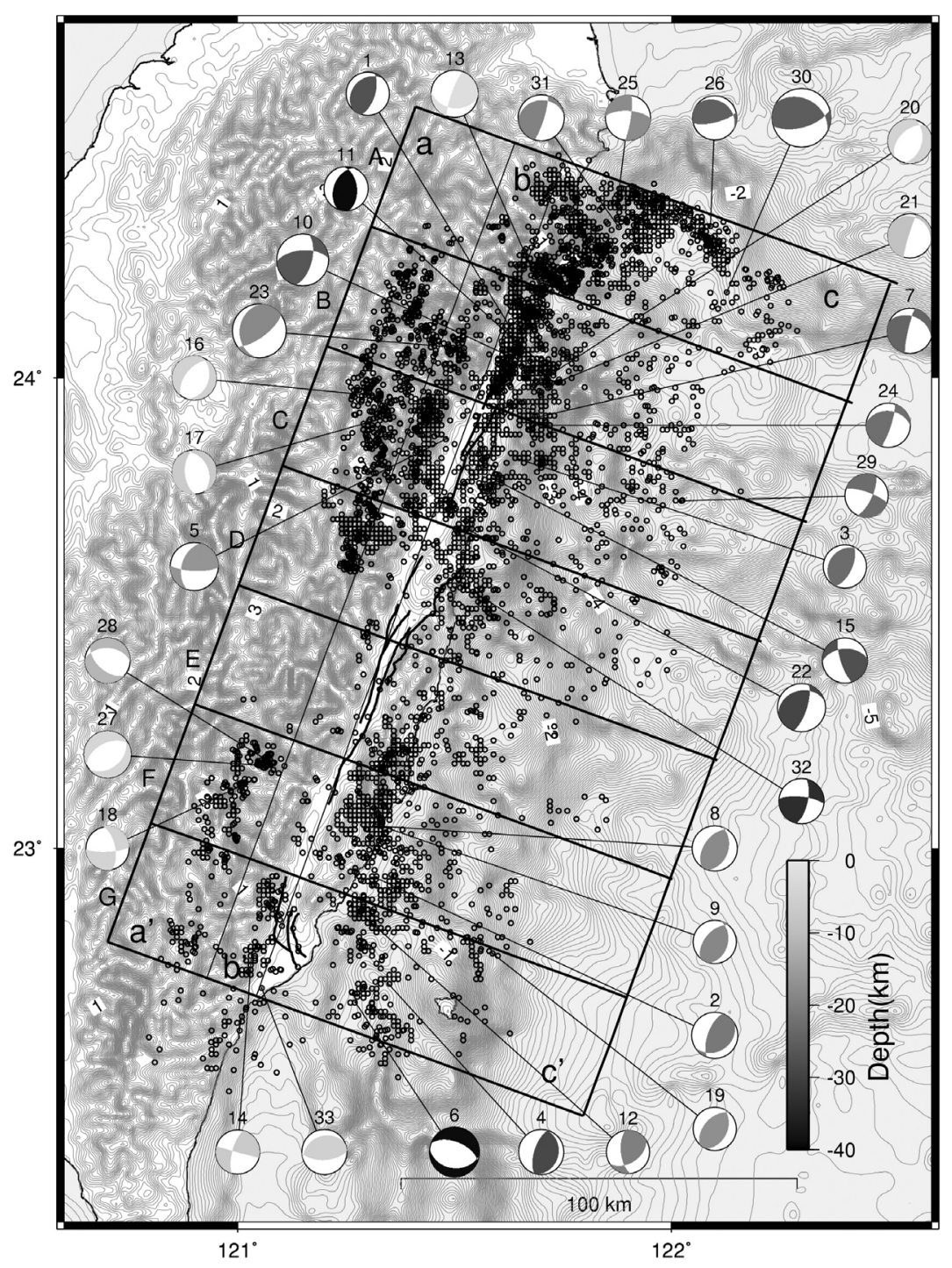

Fig. 7. Epicenters and focal mechanisms of studied earthquakes after relocated with bathymetry and the block sections of the hypocentral profiles. 

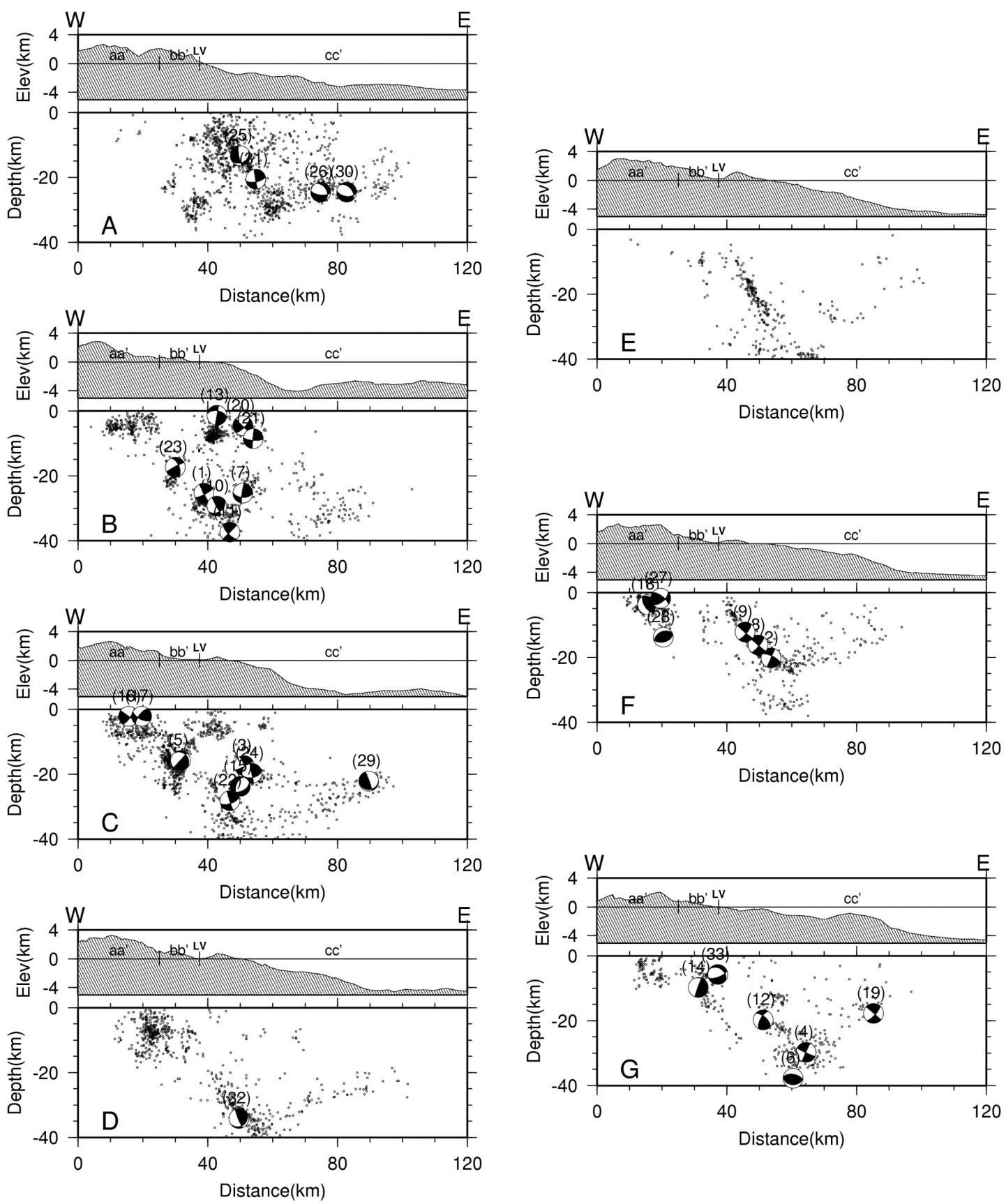

Fig. 8. The hypocentral profile and lateral projection of focal mechanisms. 
In the southern part of the study region (profiles E, F, and G in Fig. 9), the LV can be traced to be a dipping east seismic zone, this zone has a high angle in the shallow and becomes a lower angle in the deeper portion. Chen and Rau (2002), who relocated the earthquakes in the Chihshang region, also represented the seismic zone in a similar manner. Most of the events occurred above the LV extension plane and formed a very clear fault plane. The focal mechanism solutions (events: 7, 20, and 21) agree with this fault plane. There also exists a relatively seismicity prone zone under the LV extension arc plane. For profile A of Fig. 9, the earthquake distribution pattern is different to the others. Most events occurred in the offshore region; in the shallow portion (depth to $20 \mathrm{~km}$ ) there exist three clusters, one vertical and two dips to the east seismic zones. There is also a horizontal cluster that correlates to the subduction zone of the PSP in the deep portion.

According to the results from seismicity distribution and focal mechanism solutions, the seismic pattern changes greatly from the northern portion to the southern portion in eastern Taiwan. Thus, we suggest that there may exist a structure or boundary at about latitude $23.5^{\circ} \mathrm{N}$ (i.e., in about profile D of Fig. 9; the red line of Fig. 10). There are previous studies that mentioned this boundary; such as Yu and Kuo 2001, Fig.1, the GPS measurements show the different convergence rates of the northern and southern portions in eastern Taiwan. The crustal motion rates of the northern portion are half of that of the southern portion. From the marine terraces studies by Liew et al. (1990), the high uplift rates represent compression and shortening of the northwestern corner of the Philippine Sea Plate in the southern part of eastern Taiwan, and the low rates in the northern part correlate with the region where the Ryukyu Trench meets the eastern coast of Taiwan. Hsu (2001) also described a tear fault that exists between the northern and southern portion in eastern Taiwan to accommodate the reversal of subduction polarity. North of the tear fault, the subduction dips to the west while south of the tear fault, the subduction dips to the east. Moreover, the velocity structure from other research at $23.5^{\circ} \mathrm{N}$ has a discontinuous velocity structure (a differential velocity to $0.4 \mathrm{k} \mathrm{ms}^{-1}$, Cheng et al. 2002).

According to the results of this study the tectonics of eastern Taiwan can be divided into southern and northern regions (Figs. 9 and 10). The tectonics in the northern portion of eastern Taiwan are shown in Fig. 10A, the boundary between the two plates is an east-dipping plane. Most earthquakes occurred in this boundary. Also most of the focal mechanism solutions determined in this zone show thrust-type and agree with this boundary (strike $\mathrm{N} 20^{\circ} \mathrm{E}$ and dip about $50^{\circ}$ ). In the northern portion of eastern Taiwan not only the EP dips east, but also the PSP bends and dips west. Thus, in the shallow portion of the offshore area, we can observe normal-type focal mechanism events. In this region the PSP bends to the west and subducts to the north. It has resulted in complicated focal mechanism observation in the northern part of eastern Taiwan. On the other hand, the southern part of eastern Taiwan has a simpler tectonic setting (Fig. 10B). The EP subducts to the east under the PSP. The LV is a clear suture zone dipping to the east, most events occur on the right-hand side of the LV. Focal mechanism solutions of those events were thrust-type with strike about $\mathrm{N} 25^{\circ} \mathrm{E}$ and dip $54^{\circ}$ to east. This observation agrees with recent GPS measurements (e.g., Yu and Chen 1994; Yu et al. 1997). In the southern part of eastern Taiwan, the suture zone can be traced from the LV to the South Longitudinal Trough (SLT). And there also exists a shallow seismic zone with the LV extended line going southward of Taitung (near the Luyeh fault; Figs. 1 and 7) and where a 


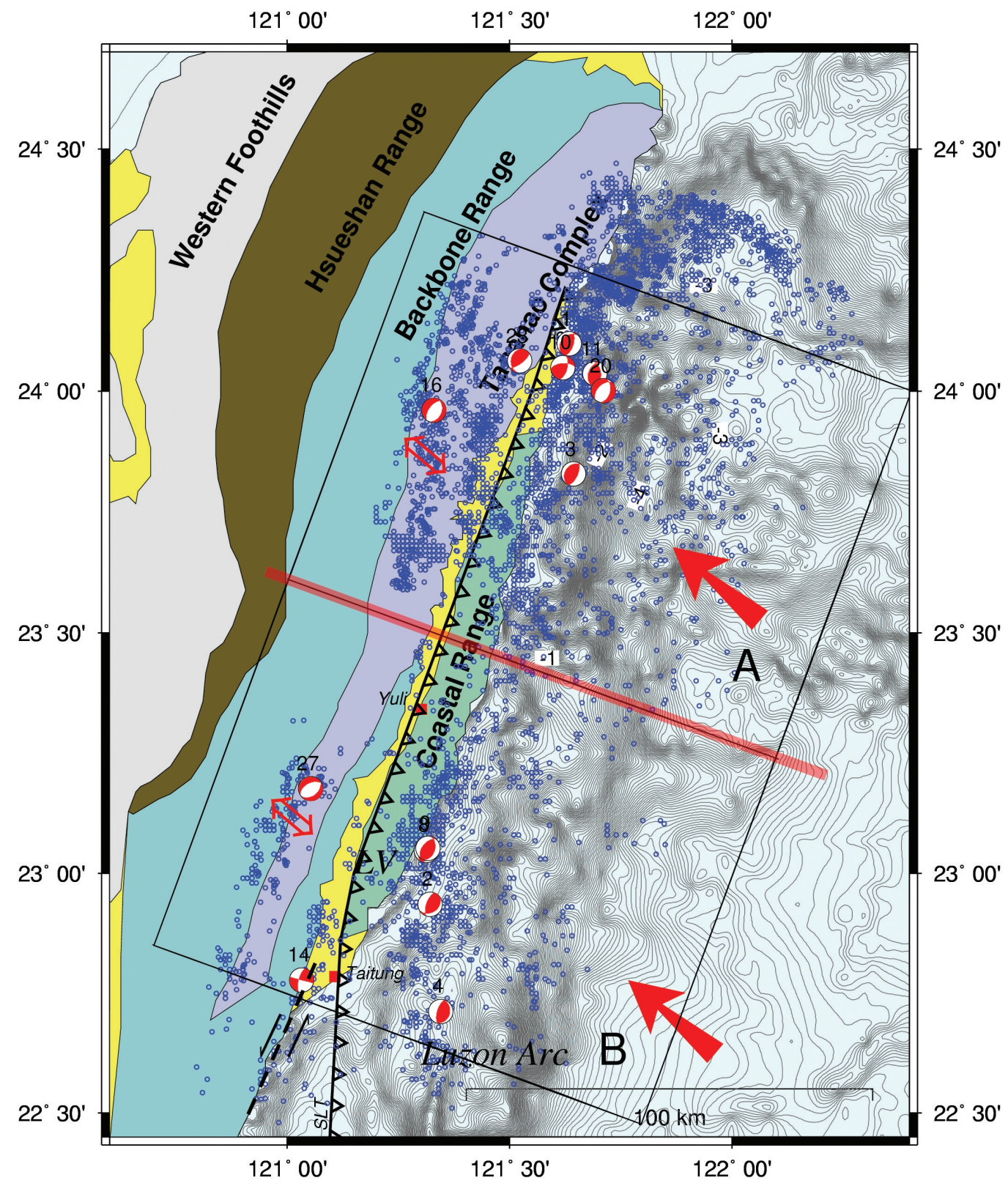

Fig. 9. The map view of modeling eastern Taiwan Tectonic implications. The detail descriptions are in this text. 

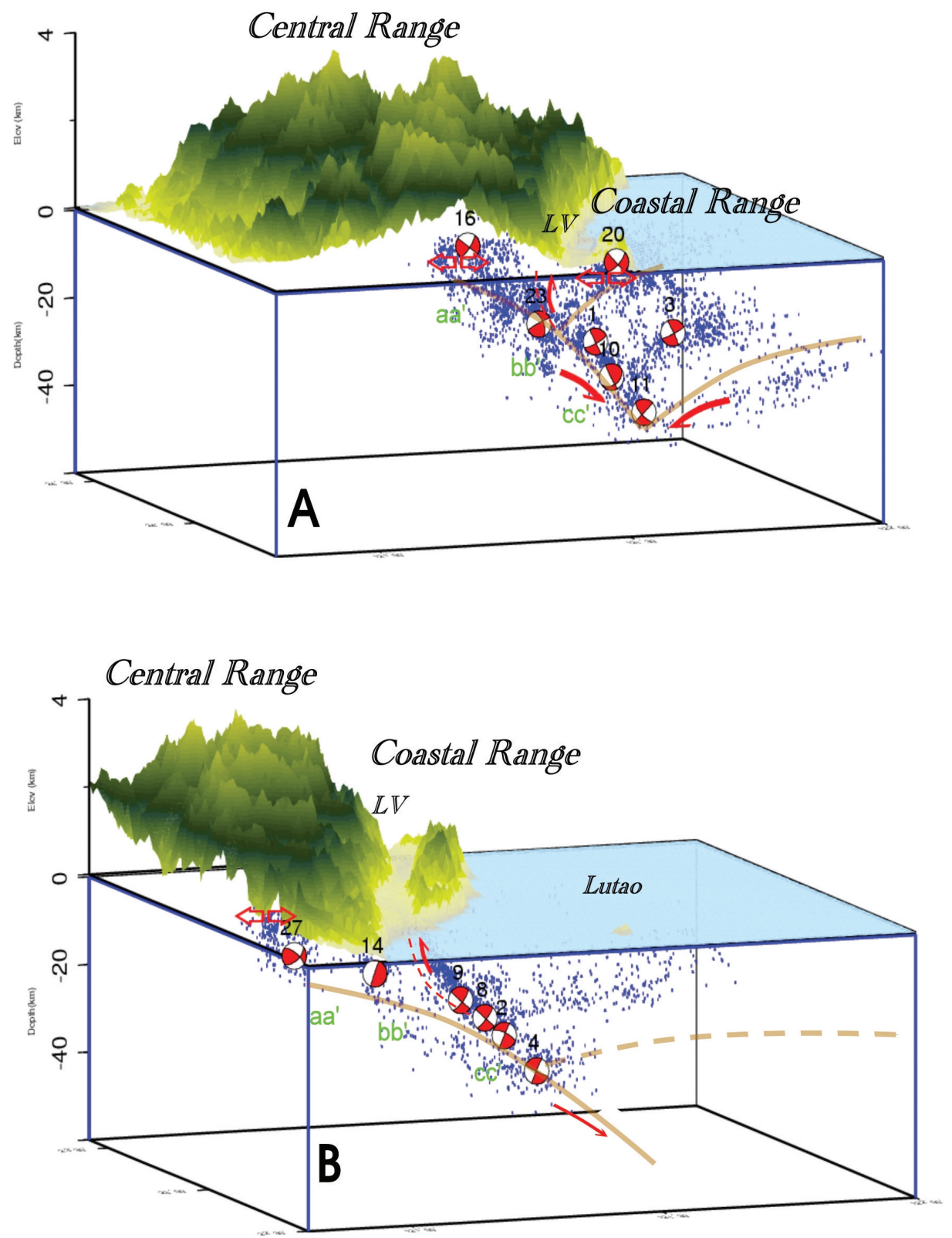

Fig. 10. 3-D view of modeling eastern Taiwan tectonic implications. Detailed descriptions are in this text. 
strike-slip focal mechanism event (event 16) was observed in this study. Geological and topographical studies also indicate that the N-S trending left-lateral shearing and transpression structures dominate along the eastern boarder of the southern Central Range (Lu et al. 2001). So that we suggest there may exist a strike-slip fault in the LV extend line southward of Taitung (Fig. 9).

Acknowledgements The authors wish to thank Dr. Willie Lee for improving the manuscript. This research was supported by the Central Weather Bureau and the National Science Council of the Republic of China under Grant No. NSC 91-2116-M-052-001 and NSC92-2119-M052-003.

\section{REFERENCES}

Angelier, J., H. T. Chu, J. C. Lee, and J. C. Hu, 2000: Active faulting and earthquake hazard: The case study of continuous monitoring of the of the Chihshang Fault, Taiwan. $J$. Geodynamics, 29, 151-185.

Barrier, E. and J. Angelier, 1986: Active collision in eastern Taiwan: The Coastal Range. Tectonophys., 125, 39-72.

Chang, C. P., J. Angelier, and C. Y. Huang, 2000: Origin and evolution of a melange: the active plate boundary and suture zone of the Longitudinal Valley, Taiwan.Tectonophys., 325, 43-62.

Chemenda, A. I., R. K. Yang, C. H. Hsieh, and A. L. Groholsky, 1997: Evolutionary model for the Taiwan collision based on physical modeling. Tectonophys., 274, 253-274.

Chemenda, A. I., R. K. Yang, J. F. Stephan, E. A. Konstantinovskaya, and G. M. Ivanov, 2001: New results from physical modeling of arc-continent collision in Taiwan: evolutionary model. Tectonophys., 333, 159-178.

Chen, H. H., and R. J. Rau, 2002: Earthquake Locations and Focal Mechanisms in an Active Arc-Continent Plate Boundary: the Chihshang Fault of Eastern Taiwan, EOS Trans. $A G U, \mathbf{8 3}$, Fall Meet. Suppl., Abs. T61-1277.

Chen, W. S., 1989: Tectonic evolution of sedimentary basins in the Coastal Range, Taiwan. Ph. D. Dissert., Nat. Taiwan Univ., Taipei.

Chen, Y. L., and T. C. Shin, 1998: Study on the earthquake location of 3-D velocity structure in Taiwan area. Meteor. Bull., 42, 135-169.

Cheng, W. B., and C. Wang, 2001: Seismogenic zones in the convergent margin, eastern Taiwan and its implications in the Luzon forearc deformation.TAO, Suppl. Issue, May 2001, 269-386.

Cheng, W. B., C. Wang, C. T. Shyu, and T. C. Shin, 2002: Crustal structure of the convergent plate-boundary zone, eastern Taiwan, assessed by seismic tomography. In: Byne, T. B., and C. S. Liu, (Eds.), Geology and Geophysics of an Arc-Continent collision, Taiwan, Republic of China. Boulder, Colorado, Geol. Soc. of Am. Special Paper 358, 161-175. 
Crespi, J., Y. C. Chan, and M. Swaim, 1996: Synorogenic extension and exhumation of the Taiwan hinterland. Geology, 24, 247-250.

Crespi, J., 1996: Deformation partitioning at shallow crustal levels in the Taiwan arc-continent collision zone. J. Geol. Soc. China, 39, 143-150.

Flinn, E. A., 1965: Confidence regions and error determinations for seismic event location. Rev. Geophy., 3, 157-185.

Ho, C. S., 1986: A synthesis of the geologic evolution of Taiwan. Tectonophys., 125, 1-16.

Hsu, S. K., 2001: Subduction/collision complexities in the Taiwan-Ryukyu junction area: tectonics of the northwestern corner of the Philippine Sea plate.TAO, Suppl. Issue, May 2001, 209-230.

Kao, H., and P. R. Jian, 2001: Seismogenic patterns in the Taiwan region: insights from source parameter inversion of BATS data. Tectonophys., 333, 179-198.

Lee, J. C., J. Angelier, H. T. Chu, J. C. Hu, F. S. Jeng, and R. J. Rau, 2003: Active fault creep variations at Chihshang, Taiwan, revealed by creepmeter monitoring, 1998-2001.J. Geophys. Res., 4, 1-21.

Lee, T.Q., C. Kissel, E. Barrier, C. Laj, and W. R. Chi, 1991: Paleomagnetic evidence for a diachronic clockwise rotation of the Coastal Range, eastern Taiwan. Earth Planet. Sci. Lett., 104, 245-257.

Liew, P. M., M. L. Hsieh, and C. K. Lai, 1990: Tectonic significance of Holocene marine terraces in the Coastal Range, eastern Taiwan. Tectonophys., 183, 121-127.

Lin, C. H., Y. H. Yeh, H. Y. Yen, K. C. Chen, B. S. Huang, S. W. Roecker, and J. M. Chiu, 1998: Three-dimensional elastic wave velocity structure of the Hualien region of Taiwan. Tectonics, 17, 89-103.

Lin, C.H., 2002: Active continental subduction and exhumation: the Taiwan orogeny.Terra Nova., 14, 281-287.

Liu, C. S., S. Y. Liu, G. S. Song, C. T. Shyu, H. S. Yu, L. Y. Chiaw, and C. Wang, 1996: Digital morphological file in the offshore region around Taiwan, Abs. Annual Meeting of Geol. Soc. China, 420-425. (in Chinese)

Liu, C. S., S. Y. Liu, S. E. Lallemand, N. Lundberg, and D. Reed, 1998: Digital elevation model offshore Taiwan and its tectonic implications. TAO, 9, 705-738.

Lu, C. Y., K. J. Chang, J. Malavieille, Y. C. Chan, and J. C. Lee, 2001: Structural evolution of the southeastern Central Range, Taiwan. Western Pacific Earth Sci., 1, 213-226.

Malavieille, J., S. E. Lallemand, S. Domingquez, A. Deschamps, C. Y. Lu, C. S. Liu, P. Schnürle, and the ACT Scientific Crew, 2002: Arc-continent collision in Taiwan: New marine observations and tectonic evolution. In: Byne, T. B., and C. S. Liu, (Eds.), Geology and Geophysics of an Arc-Continent collision, Taiwan, Republic of China: Boulder, Colorado, Geol. Soc. of Am. Special Paper 358, 187-211.

Rau, R. J., and F. T. Wu, 1998: Active tectonics of Taiwan orogeny from focal mechanisms of small-to-moderate-sized earthquakes. TAO, 9, 755-778.

Teng, L. S., 1990: Geotectonic evolution of late Cenozoic arc-continent collision in Taiwan. Tectonophys., 183, 57-76. 
Thurber, C. H., 1993: Local earthquake tomography: velocities and Vp/Vs- theory, in Seismic Tomography: Theory and practice. Iyer H. M., and K. Hirahara, (Eds.), Chapman \& Hall, London, U.K.

Thurber, C., and D. Eberhart-Phillips, 1999: Local earthquake tomography with flexible gridding. Comp. Geosci., 25, 809-818.

Tsai, Y. B., 1986: Seismotectonics of Taiwan. Tectonophys., 125, 17-37.

Waldhauser, F., and W. L. Ellsworth, 2000: A double-difference earthquake location algorithm: method and application to the northern Hayward fault, California. Bull. Seis. Soc. Am., 90, 1353-1368.

Wang, W. H., and W. J. Hung, 2002: Synorogenic extension, Taiwan: Implications of physical and numerical modeling, In: Byne, T. B., and C. S. Liu, (Eds.), Geology and Geophysics of an Arc-Continent collision, Taiwan, Republic of China: Boulder, Colorado, Geol. Soc. of Am. Special Paper 358, 137-146.

Wu, F. T., 1978: Recent tectonics of Taiwan. J. Phys. Earth, 26, S265-S299.

Wu, F. T., R. J Rau, and D. Salzberg, 1997: Taiwan orogeny: thin-skinned or lithospheric collision? Tectonophys., 274, 191-220.

Wu, Y. M., C. H. Chang, Y. B. Tsai, J. K. Chung, T. C. Shin, and C. Y. Wang, 1998: Improvement on earthquake location by using near-source $P \& S$ arrivals and $\mathrm{S}$-P time differences. $7^{\text {th }}$ Taiwan symposium on geophysics, $1998.165-180$.

Yu, S. B., D. D. Jackson, G. K. Yu, and C. C. Liu, 1990: Dislocation model for crustal deformation in the Longitudinal Valley area, eastern Taiwan. Tectonophys., 183, 97-109.

Yu, S. B., and H. Y. Chen, 1994: Global positioning system measurement of crustal deformation in the Taiwan arc-continent collision zone.TAO, 5, 477-498.

Yu, S. B., H. Y. Chen, and L. C. Kuo, 1997: Velocity field of GPS stations in the Taiwan area. Tectonophys., 274, 41-60.

Yu, S. B., and L. C. Kuo, 2001: Present-day crustal motion along the Longitudinal Valley fault, eastern Taiwan. Tectonophys., 333, 199-217. 